\title{
AS PRÁTICAS DE CONTROLO DE GESTÃo E A PERFORMANCE FINANCEIRA DE UM GRUPO PORTUGUÊS INSERIDO NO SETOR DAS ATIVIDADES DE INFORMAÇÃO E COMUNICAÇÃO
}

\section{MANAGEMENT CONTROL PRACTICES AND FINANCIAL PERFORMANCE OF A PORTUGUESE GROUP IN THE INFORMATION AND COMMUNICATION ACTIVITIES SECTOR}

\author{
Recebido em: 19/03/2021 \\ Aprovado em: 27/05/2021 \\ Alexandra Domingos \\ Instituto Politécnico de Lisboa (IPL) \\ Instituto Superior de Contabilidade e Administração de Lisboa (ISCAL) \\ Portugal \\ ORCID: 0000-0002-5521-8221 \\ Email: amrodrigues@,iscal.ipl.pt \\ Beatriz Mendonça \\ Instituto Politécnico de Lisboa (IPL) \\ Instituto Superior de Contabilidade e Administração de Lisboa (ISCAL) \\ Portugal \\ ORCID: 0000-0001-6640-0777 \\ Email: beatrizccmendonca@gmail.com
}

\section{RESUMO}

O presente artigo tem como objetivo analisar, ao longo do período 2014-2018, a influência que a utilização de sistemas de controlo de gestão, implementados por um grupo português do setor das Atividades de Informação e Comunicação, tem na sua performance financeira. Para o efeito, foi utilizada a metodologia do estudo de caso, tendo-se recolhido informações através de reuniões, observação direta e análise documental. Concluiu-se que, nos anos de 2014 e 2015, a alteração existente nos sistemas de controlo de gestão na fase de controlo retrospetivo, contribuiu de forma positiva para a melhoria dos indicadores de volume de negócios, EBITDA e rendibilidade dos capitais próprios. O aperfeiçoamento dos sistemas na fase de controlo integrado gerou um aumento do volume de negócios, da rendibilidade dos capitais próprios e da autonomia financeira, em 2016 e 2017. No ano 2018, verificou-se uma quebra nos indicadores volume de negócios e EBITDA. Com base nos resultados, sugeriram-se algumas propostas de melhoria dos sistemas de controlo de gestão adotados.

Palavras-chave: Controlo de Gestão, Orçamentos, Planeamento, Media, Desempenho. 


\begin{abstract}
This article aims to analyze, over the period 2014-2018, the influence that the use of management control systems implemented by a portuguese group in the Information and Communication Activities sector, has on its financial performance. For this purpose, the case study methodology was used and information was collected through meetings, direct observation and documentary analysis. It was concluded that, in 2014 and 2015, the change in management control systems in the retrospective control phase, contributed positively to the improvement of turnover, EBITDA and return on equity indicators. The improvement of systems in the integrated control phase generated an increase in turnover, return on equity and financial autonomy, in 2016 and 2017. In 2018, there was a fall in the turnover and EBITDA indicators. Based on the results, some proposals for improving the management control systems adopted were suggested.
\end{abstract}

Keywords: Management Control, Budgets, Planning, Media, Performance.

\title{
1 INTRODUÇÃO
}

Com a mudança ocorrida no contexto empresarial, fatores como os recursos intangíveis, nomeadamente, as pessoas e a estratégia, ganharam maior relevo. São estes dois fatores integrados que o Controlo de Gestão (CG) procurar alinhar para estimular o sucesso das empresas. O comportamento das pessoas e a implementação da estratégia, devem ser alinhados através de instrumentos de controlo que permitam a convergência de interesses entre colaboradores e organizações (Merchant \& Van der Stede, 2012; Kaplan \& Norton, 1992).

De acordo com Anthony e Govindarajan (2007), o campo de ação do CG é conseguir executar a estratégia das entidades através do desenvolvimento de instrumentos práticos de gestão. Ou seja, o objetivo do CG, consiste em controlar as decisões e ações tomadas pela gestão com base em instrumentos de controlo, como por exemplo, o Balanced Scorecard (BSC), avaliando processos de planeamento e analisando os orçamentos efetuados, a fim de comparar, futuramente, todos estes aspetos com a consequente performance financeira.

Ao longo do tempo, alguns estudos têm vindo a debruçar-se sobre as relações existentes entre a implementação de sistemas de controlo de gestão (SCG) e a performance das empresas (Silva, 2018; Duréndez et al., 2016; Morais, 2016; Texeira, Antunes \& Quirós, 2015; Muanha, 2014; Rendas, 2013).

Verifica-se que na literatura, os estudos sobre os SCG são essencialmente focados nos diferentes tipos de sistemas existentes ou no desenvolvimento daqueles. Este estudo contribui para a literatura existente, na medida em que pretende relacionar a adoção de SCG e a sua performance financeira, uma vez que não existem pesquisas anteriores relativas a este tema, neste setor. Surgiram evidências de que, no grupo objeto de estudo, os SCG não se adequam à sua realidade atual. Portanto, ambos os fatores foram os motores da discussão sobre esta temática.

Neste sentido, o objetivo deste artigo é analisar, ao longo do período de 2014 a 2018, a influência que a utilização de SCG implementados por um grupo português do setor das Atividades de Informação e Comunicação (AIC), tem na sua performance financeira. Através de um estudo de caso, realizaram-se reuniões com o controller e a contabilista certificada do 
grupo. Além disso, os documentos que apoiaram o estudo e a observação direta também contribuíram para a recolha de informações.

O estudo de caso desenvolvido concluiu que não é possível afirmar que a intensidade da utilização mais elevada de SCG durante o período em análise, conduziu a melhores resultados financeiros. Ou seja, não se pode afirmar que a existência de SCG ou a intensidade da sua utilização conduz a uma performance financeira superior, em detrimento de outras variáveis.

O artigo está estruturado da seguinte forma: a secção 2 contextualiza o CG, os SCG, apresentando alguns estudos efetuados sobre a relação entre a implementação de SCG e o seu impacto na performance organizacional. A metodologia e os procedimentos utilizados para a recolha de dados durante a realização do trabalho de campo encontram-se descritos na secção 3. A secção 4 apresenta o estudo de caso desenvolvido e na secção 5 são apresentados os SCG adotados pelo grupo ao longo do período em análise. Por fim, a secção 6 apresenta as considerações finais, limitações do estudo e sugestões de investigação futura.

\section{REFERENCIAL TEÓRICO}

\subsection{O Controlo de Gestão}

O ambiente do qual as organizações fazem parte é cada vez mais competitivo. Como tal, a gestão das organizações está constantemente dependente da obtenção de informação adequada e privilegiada para suportar a tomada de decisão. Deste modo, o CG tem vindo progressivamente a ganhar cada vez mais importância como apoio à tomada de decisão, sendo, atualmente, uma função crítica de qualquer organização. Eventuais falhas neste processo podem ter consequências graves para as organizações, e podem traduzir-se em perdas financeiras, danos à reputação e, em algumas situações, falência (Merchant \& Van der Stede, 2012).

Ussahawanitchakit (2017) refere que o CG é fundamental e que desempenha um papel significativo na determinação da vantagem competitiva nas empresas. $\mathrm{O}$ autor reconhece o CG como uma ferramenta preciosa, que pode ser utilizada para melhorar a sustentabilidade nas operações futuras, a longo prazo.

Jordan et al. (2015, p. 28) afirmam que o CG é "o esforço permanente realizado pelos principais responsáveis da empresa para atingir os objetivos fixados", entendendo por "principais responsáveis" os gestores e os responsáveis operacionais, resumindo todo o processo em 3 fases (Figura 1): 


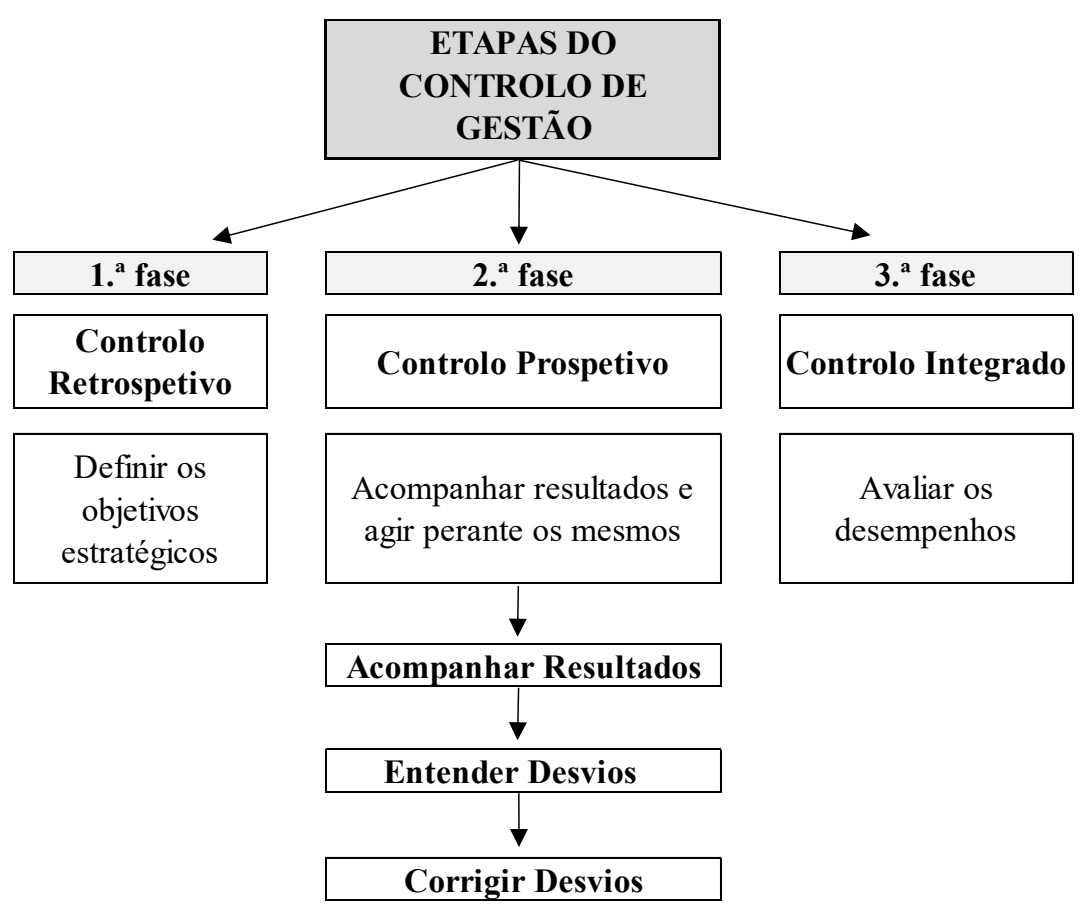

Figura 1. Etapas do Controlo de Gestão Fonte: Elaboração Própria.

Para Jordan et al. (2015), é na $1^{\mathrm{a}}$ fase que se estabelecem claramente quais são os objetivos estratégicos da empresa, o que permitirá à gestão, de forma prática e quantificável, definir os standards. A $2^{\text {a }}$ fase deve ser feita numa base periódica regular e está dividida em três etapas: a primeira consiste na comparação da performance com o que foi previamente previsto/estipulado; a segunda consiste na análise e entendimento das causas para os desvios que possam existir; e, a terceira é a criação de medidas corretivas para os desvios detetados. Por fim, na $3^{\text {a }}$ fase, o objetivo do controlo é extrair conclusões acerca da performance da empresa, considerando a atuação das duas primeiras fases anteriormente referidas.

Desta forma, os autores referem que avaliar o desempenho das diferentes áreas da empresa permite à gestão executar uma manobra de sansão ou recompensa conforme o esperado e o estipulado para cada área e/ou responsável de área e permite, ainda, servir de base para a elaboração dos objetivos e respetivos planos de ação para o período seguinte.

De acordo com a revisão da literatura efetuada, verifica-se que o CG é o processo pelo qual a empresa assegura que a utilização e/ou transformação dos inputs, e correspondentes outputs que daí resultam, está a ser realizada da forma mais eficiente e eficaz. É, portanto, a forma que as empresas usam para assegurar que toda a atividade económica está a ser realizada de acordo com os objetivos estratégicos, previamente definidos pelo órgão de gestão. A função controlo permite, assim, não apenas assegurar que as atividades estão a ser desempenhadas conforme esperado, mas também prever e detetar possíveis desvios que possam ocorrer, bem como formular as respetivas medidas de correção necessárias.

\subsection{A implementação de SCG e a sua relação com a performance organizacional}

Os SCG desempenham um papel essencial à vitalidade das entidades. No entanto, Barros e Ferreira (2019), referiram que uma vez que se trata de um conceito com uma 
evolução relativamente recente, tem sido bastante difícil encontrar consenso em apenas uma só definição de SCG.

Alguns autores definem SCG como sendo o conjunto de mecanismos que os gestores utilizam de forma a assegurar que os comportamentos e decisões dos seus colaboradores vão ao encontro dos objetivos da organização (Merchant \& Van der Stede, 2012; Malmi \& Brown, 2008).

A Figura 2 evidencia um SCG simplificado, que contém alguns dos mecanismos de controlo que as entidades devem adotar.

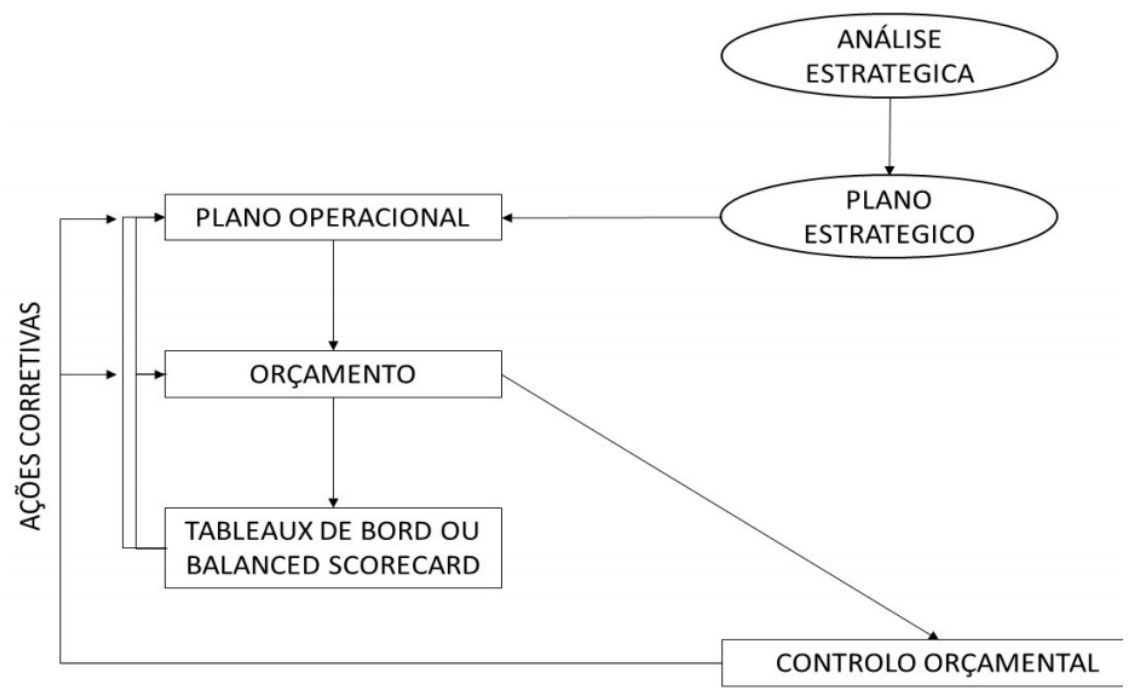

Figura 2. Exemplo de SCG simplificado Fonte: Jordan et al. (2015, p. 42).

A Figura 2 representa, assim, um SCG como um esquema dinâmico de atividades que deve começar com uma análise estratégica, capaz de fundamentar a criação do plano estratégico, traduzindo-se na prática através de um plano operacional. Esse plano operacional, traduz-se monetariamente num orçamento. O controlo dos níveis de cumprimento dos orçamentos, face aos planos estratégicos pode ser feito através de ferramentas como o Tableaux de Bord (TdB) e/ou o BSC.

Jordan et al. (2015) consideram que os instrumentos de pilotagem são constituídos pelo plano operacional e orçamental, pelo controlo orçamental e pelo TdB ou pelo BSC. São, também, apresentados outros dois instrumentos - análise estratégica e plano estratégico - que são essenciais ao entendimento do conceito de SCG e à sua implementação.

Existem diferentes razões para que se possa considerar que os SCG proporcionam uma melhoria considerável na performance das empresas, sobretudo pelo facto destes sistemas estarem direcionados para alcançar os resultados pretendidos, promovendo a definição dos objetivos e aumentando a eficiência no que diz respeito à resolução de questões relacionadas com as tarefas desempenhadas (Duréndez et al., 2016).

Rendas (2013) analisou o impacto da utilização dos SCG, da estratégia implementada, da dimensão e da perceção dos clientes no desempenho financeiro de 66 Pequenas e Médias Empresas (PMEs) portuguesas do setor hoteleiro, no período de 2011. A autora concluiu que uma maior utilização do planeamento financeiro está associada à obtenção de melhores resultados. No entanto, não foi possível afirmar que a utilização desta categoria, em detrimento das restantes, levou a um desempenho financeiro superior. 
Por outro lado, Muanha (2014) estudou a relação entre o desempenho das organizações financeiras e condicionantes como a liderança, a motivação, a competência, as regras de trabalho do CG. O estudo foi aplicado através de um questionário a 42 funcionários bancários portugueses, tendo-se concluído que quanto maior e mais clara for a definição de regras e de objetivos de trabalho, maior será o nível motivacional dos funcionários, logo maior será a competência e o conhecimento aplicado na performance do CG.

Duréndez et al. (2016) analisaram o grau de utilização dos SCG com o seu impacto na performance de 900 PMEs espanholas. Através de 40 questionários aos gestores de empresas familiares e não familiares, os autores confirmaram que o uso dos SCG tem um efeito positivo na performance das empresas, tanto familiares como não familiares. Concluíram, também, que a dimensão da empresa é uma variável relevante para explicar o grau de utilização dos SCG, bem como a sua performance: empresas maiores utilizam mais intensamente os SCG e obtêm melhores desempenhos. A idade da empresa demonstrou ter uma relação com a sua performance, especialmente nas empresas não familiares. No entanto, não se verifica relação significativa com o grau de utilização dos SCG.

Morais (2016) analisou a relação entre os SCG adotados por 44 farmácias comunitárias portuguesas e a sua performance financeira, no ano 2015. A autora concluiu que, embora sejam inúmeras as vantagens da adoção de SCG, nomeadamente, facilitar os processos de tomadas de decisão e, ainda, desenvolver a inovação de uma empresa, esta variável não se revelou, em nenhum teste efetuado, relevante para um melhor desempenho das farmácias.

Silva (2018) inquiriu 98 empresas portuguesas com o objetivo de saber qual a relação entre a existência de um departamento de CG e o desempenho organizacional, tendo concluído com $66,7 \%$ de convicção, que o CG e o desempenho organizacional são dois temas dependentes entre si.

Não obstante, o estudo efetuado por Texeira, Antunes e Quirós (2015) refere que a existência de SCG por si só não implica uma melhoria da rendibilidade. Os autores afirmaram que não se trata de uma relação estanque e independente de outros fatores, como por exemplo restruturações internas ou imposições sociopolíticas ou até mesmo por questões de saúde pública. Quer isto dizer que, embora os SCG possam ter um efeito positivo nos resultados operacionais e financeiros das organizações, não é possível assumir que este fator isolado permite aumentar a rendibilidade, uma vez que outros fatores estarão também presentes.

\section{METODOLOGIA DE INVESTIGAÇÃO}

Para cumprir com o objetivo geral são propostos os seguintes objetivos específicos: (i) $i$ dentificar e descrever os SCG utilizados pelo grupo; (ii) comparar os SCG existentes com a performance financeira ao longo do período 2014-2018; e (iii) propor medidas que contribuam para a melhoria da performance do mesmo, através da melhoria dos SCG atualmente implementados.

A metodologia utilizada na investigação realizada foi o estudo de caso, considerado provavelmente a melhor abordagem metodológica de investigação para utilizar como estudo ideal para descrever contextos complexos e compreender, explorar e descrever acontecimentos (Yin, 2018). Tratando-se de um estudo de caso aplicado a um caso concreto utilizou-se uma abordagem metodológica de natureza qualitativa. A abordagem qualitativa utiliza como métodos de investigação: as entrevistas; a observação; os textos e documentos e o registo áudio e vídeo (Vieira, Major \& Robalo, 2009). No caso estudado, foram recolhidos 
dados qualitativos de quatro fontes diferentes: documentação, registos em arquivo, reuniões com o controller e a contabilista certificada do grupo e observação direta. A veracidade e fiabilidade da evidência recolhida foram garantidas através da utilização de diferentes fontes de informação, garantindo a multiplicidade de evidências que aumentam a credibilidade do estudo (Yin, 2018).

Uma vez que o estudo de caso pretende averiguar quais os procedimentos/métodos de planeamento utilizados pelo grupo-alvo de estudo; avaliar os SCG implementados e constatar o impacto que estes têm na performance financeira; este será mais orientado para a análise dos processos e do seu contributo do que para os resultados obtidos.

A recolha de dados consistiu na análise de documentos internos disponibilizados pelo grupo, tais como: Relatórios \& Contas $(\mathrm{R} \& \mathrm{C})$; procedimentos internos do SCG e BSC para o período de 2014 a 2018. A outra fonte de recolha de dados utilizada foi o arquivo de registos da organização, que permitiu obter informações pertinentes sobre a sua estratégia, visão, missão e objetivos. A observação direta e participante foi a outra fonte de recolha de dados utilizada. Das várias fontes de dados existentes, o recurso ao método de observação, e em particular ao método de observação participante, é um dos que melhor justifica a análise das evidências recolhidas, dada a relação entre a autora da investigação e a empresa de estudo.

A principal fonte de evidência para a elaboração deste estudo foram as reuniões com o controller e a contabilista certificada do grupo. Estas reuniões foram efetuadas sobretudo com o propósito de:

- entender o esquema de processos atualmente implementados, as ferramentas de gestão utilizadas e a dinâmica do departamento de planeamento e controlo de gestão (PCG);

- compreender as variações dos resultados ao longo do período em análise;

- identificar o planeamento estratégico e interligá-lo com a definição e operacionalização dos SCG;

- conhecer o sistema de informação existente e as regras definidas para o CG;

- conhecer a autoridade dos responsáveis departamentais sobre os recursos ao seu dispor e o âmbito da sua atividade

- saber a sua opinião relativamente ao SCG operacionalizado.

Procurou-se, com a escolha deste grupo de responsáveis, reunir as diferentes perspetivas de acordo com os níveis hierárquicos e grau de participação-influência na empresa.

\section{CARACTERIZAÇÃO DO GRUPO}

O grupo objeto de estudo, doravante designado de MEDIA, é um dos maiores e mais antigos grupos de media do país, com presença tanto em Portugal Continental como nas Regiões Autónomas. É constituído por diversas empresas com diferentes áreas de negócio, nomeadamente: elaboração e comercialização de jornais, revistas e conteúdos digitais; rádio; distribuição e impressão. O grupo detém, ainda, outras empresas localizadas no estrangeiro, que não serão alvo de estudo nesta investigação. Estas empresas apesar de estarem associadas ao grupo, não têm a Contabilidade sob a responsabilidade do grupo português (a informação é posteriormente agregada às contas do grupo, via Hyperion-Oracle, por parte da administração). 


\subsection{Análise económico-financeira do período 2014-2018}

A presente investigação teve como base para a análise da performance financeira, os indicadores financeiros definidos pelo Banco de Portugal (BdP) para analisar o setor das AIC. Esta entidade considera que, para avaliar a performance financeira de uma entidade, devem ser consideradas quatro áreas: o setor, a atividade, o financiamento e a rendibilidade. A Tabela 1 resume alguns dos indicadores a serem considerados por cada área a ser avaliada.

Tabela 1. Indicadores Financeiros de avaliação da performance

\begin{tabular}{|c|c|c|c|}
\hline \multicolumn{4}{|c|}{ Indicadores de Performance } \\
\hline \multirow{2}{*}{ Setor } & \multicolumn{3}{|c|}{ Entidade } \\
\hline & Atividade & Financiamento & Rendibilidade \\
\hline $\begin{array}{c}\text { Volume de } \\
\text { negócios }(\mathrm{VN}) \\
\mathrm{N}^{o} \text { de empresas } \\
\mathrm{N}^{\mathrm{o}} \text { de pessoas ao } \\
\text { serviço }\end{array}$ & $\begin{array}{l}\text { Volume de Negócios (VN) } \\
\text { Earnings Before Interest, Taxes, Depreciation } \\
\text { and Amortization (EBITDA) } \\
\text { Earnings Before Interest and Taxes (EBIT) }\end{array}$ & $\begin{array}{c}\text { Autonomia } \\
\text { Financeira (AF) }\end{array}$ & $\begin{array}{c}\text { Rendibilidade dos Capitais } \\
\text { Próprios (RCP) }\end{array}$ \\
\hline
\end{tabular}

Fonte: Elaboração Própria.

Neste ponto é, assim, efetuada uma breve análise económico-financeira, com base nos indicadores tradicionais de avaliação da performance do BdP (2014), fazendo-se a comparação com o setor. Seguidamente, as Figuras 3 a 6 apresentam os indicadores financeiros analisados.

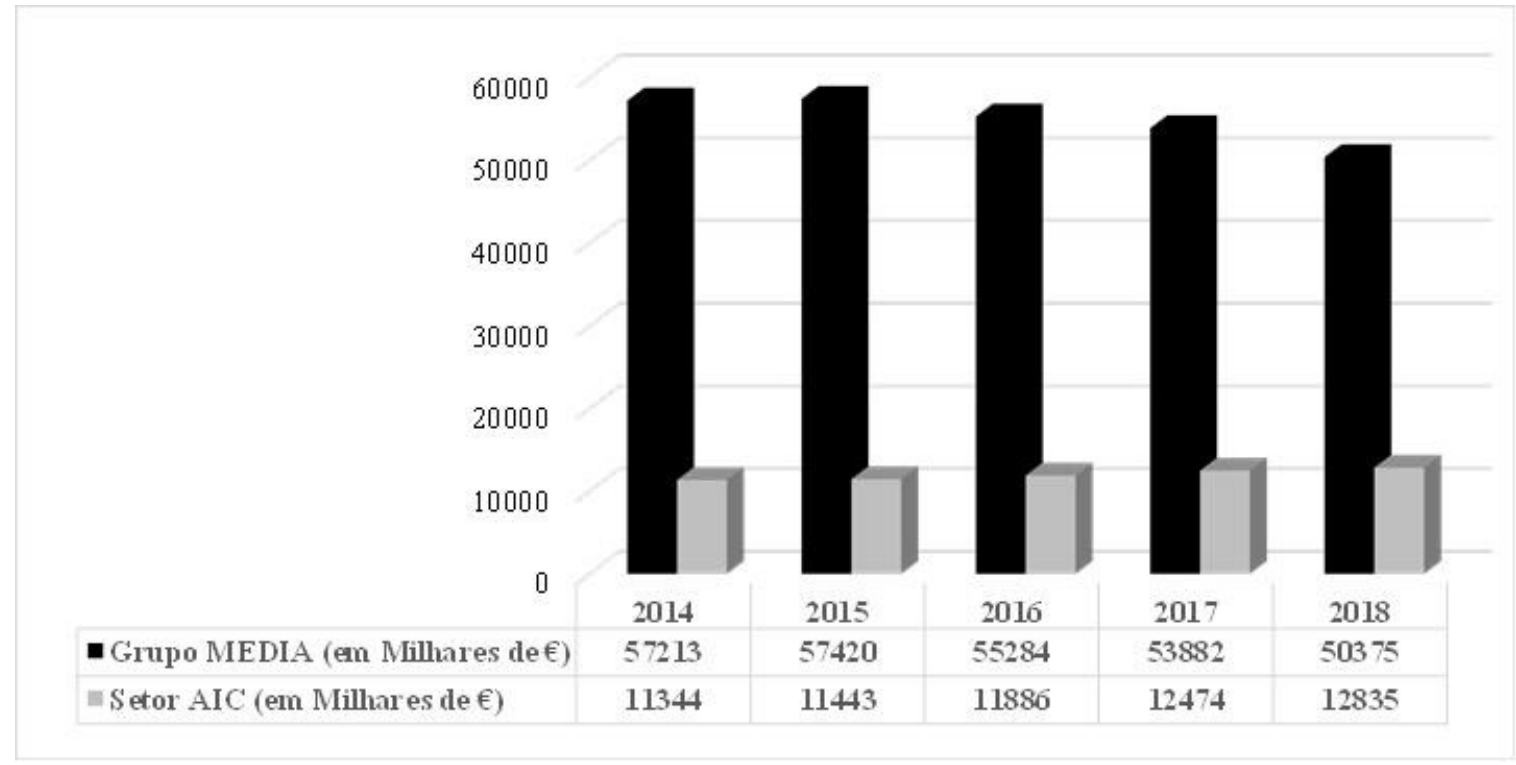

Figura 3. Evolução do VN no período 2014-2018

Fonte: Dados da pesquisa (2020).

Observando a Figura 3, verifica-se que apesar de o grupo ter atingido 57,4 milhões de euros de VN, em 2015, este indicador registou uma diminuição ao longo período em análise. Esta tendência é explicada pela acentuada diminuição de vendas de publicações impressas, justificada pelo crescente desenvolvimento tecnológico. Esta diminuição foi de 
aproximadamente $12 \%$ em 2018, face a 2015. Apesar disso, é notório o peso do grupo no setor onde se insere, uma vez que o VN representa, quase, quatro vezes mais que a média do setor.

Como se pode verificar na Figura 4, ao longo do periodo 2014-2018, o grupo registou um EBITDA negativo, chegando a aproximadamente 8,6 milhões de euros em 2018.

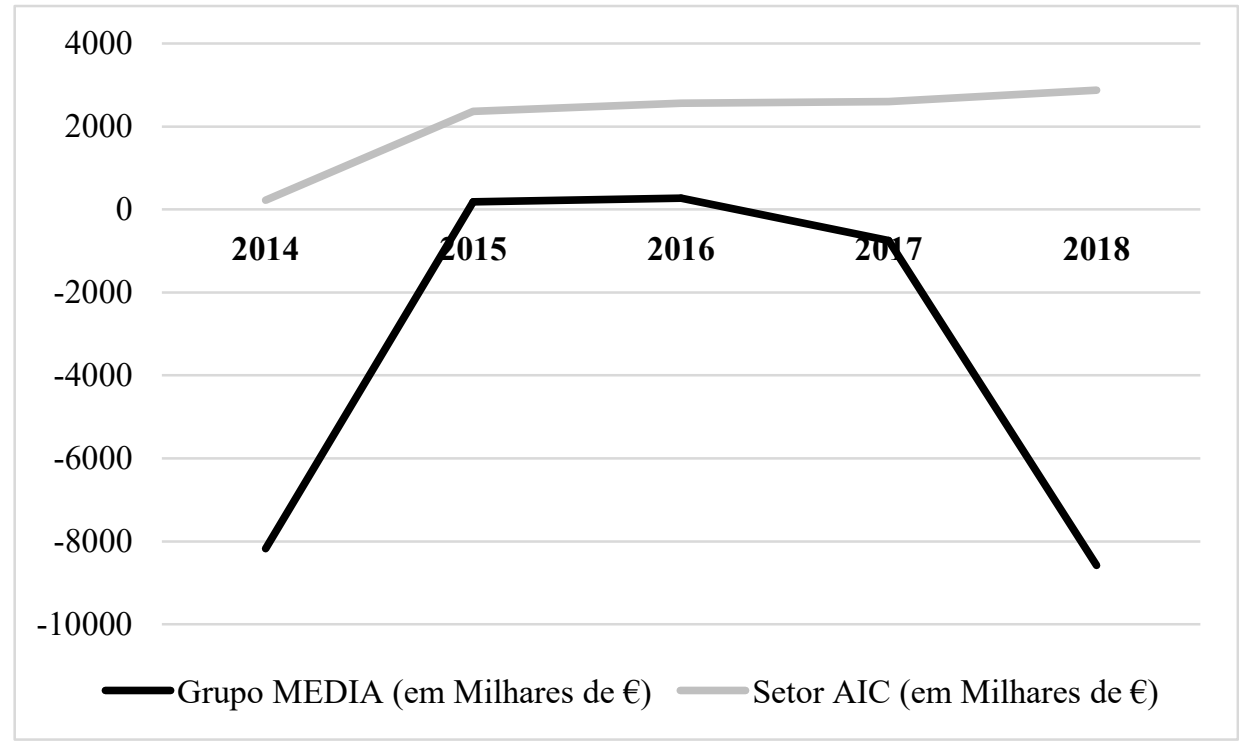

Figura 4. Evolução do EBITDA no período 2014-2018

Fonte: Dados da pesquisa (2020).

Analisando este indicador, chega-se à conclusão de que o grupo MEDIA não acompanhou a tendência de crescimento do setor, devendo-se esta situação ao facto de, tanto em 2014 como em 2018, terem existido reestruturações no grupo. Em 2014, o valor negativamente elevado do EBITDA deveu-se à entrada de novos acionistas e a um grande despedimento coletivo, originando elevados gastos com indemnizações. Em 2018, o grupo voltou a marcar o seu ano com um despedimento coletivo, e com investimentos em novos projetos, sendo os valores negativamente elevados do EBITDA em grande parte justificáveis.

Como se pode verificar na Figura 5, o grupo MEDIA, em nenhum dos anos do período em estudo, teve capacidade para remunerar os seus acionistas. Esta incapacidade é resultante dos sistemáticos resultados negativos, considerando os anos 2014 e 2018 de maior acentuação, resultante das reestruturações ocorridas. Não obstante este cenário, a perspetiva futura continua a ser a de evolução positiva, tanto do indicador da RCP como do resultado líquido do período. 


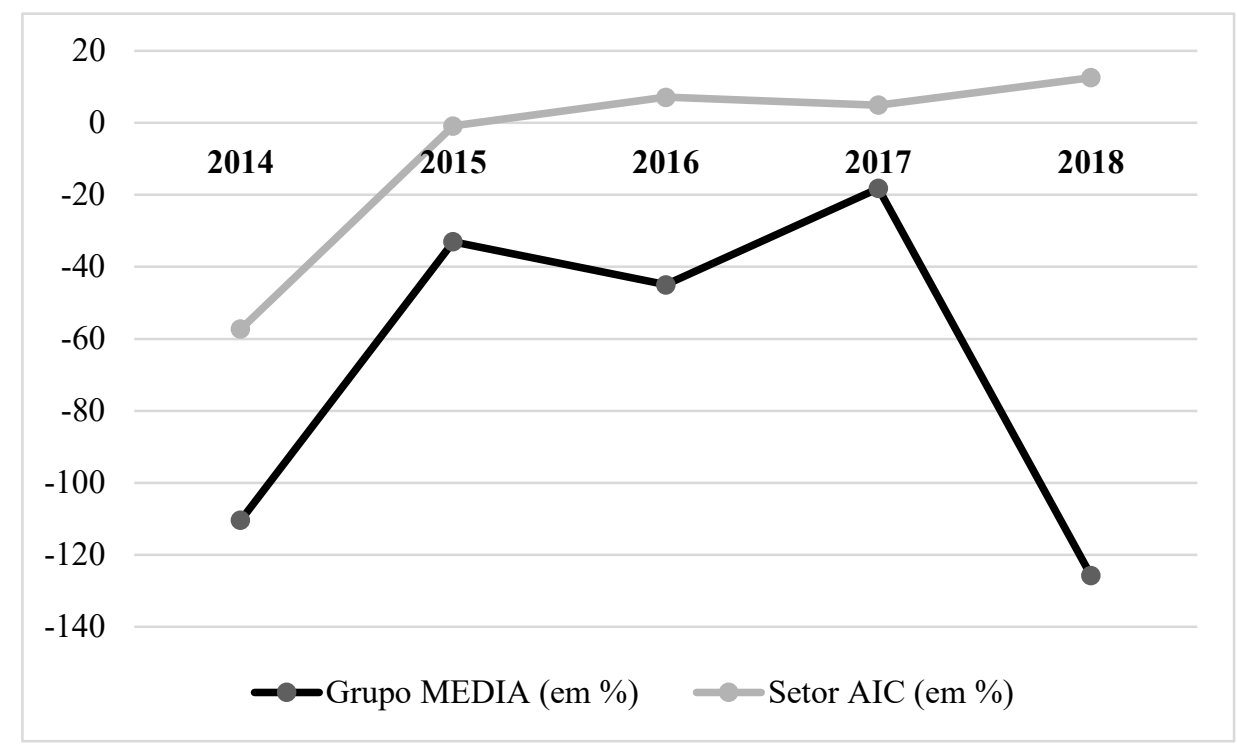

Figura 5. Evolução da RCP no período 2014-2018

Fonte: Dados da pesquisa (2020).

Da análise à Figura 6, pode concluir-se que o grupo se situou, sempre abaixo dos $30 \%$ de $\mathrm{AF}$, em todos os períodos económicos analisados tendo, no entanto, acompanhado a tendência decrescente do setor durante o período de 2014 a 2018.

A Figura 6 revela, ainda, que em 2017, o grupo MEDIA atingiu o seu auge de independência de capitais alheios e nesse mesmo ano aproximou-se mais da realidade do setor, evidenciando uma maior capacidade para fazer face aos seus compromissos financeiros através de capitais próprios.

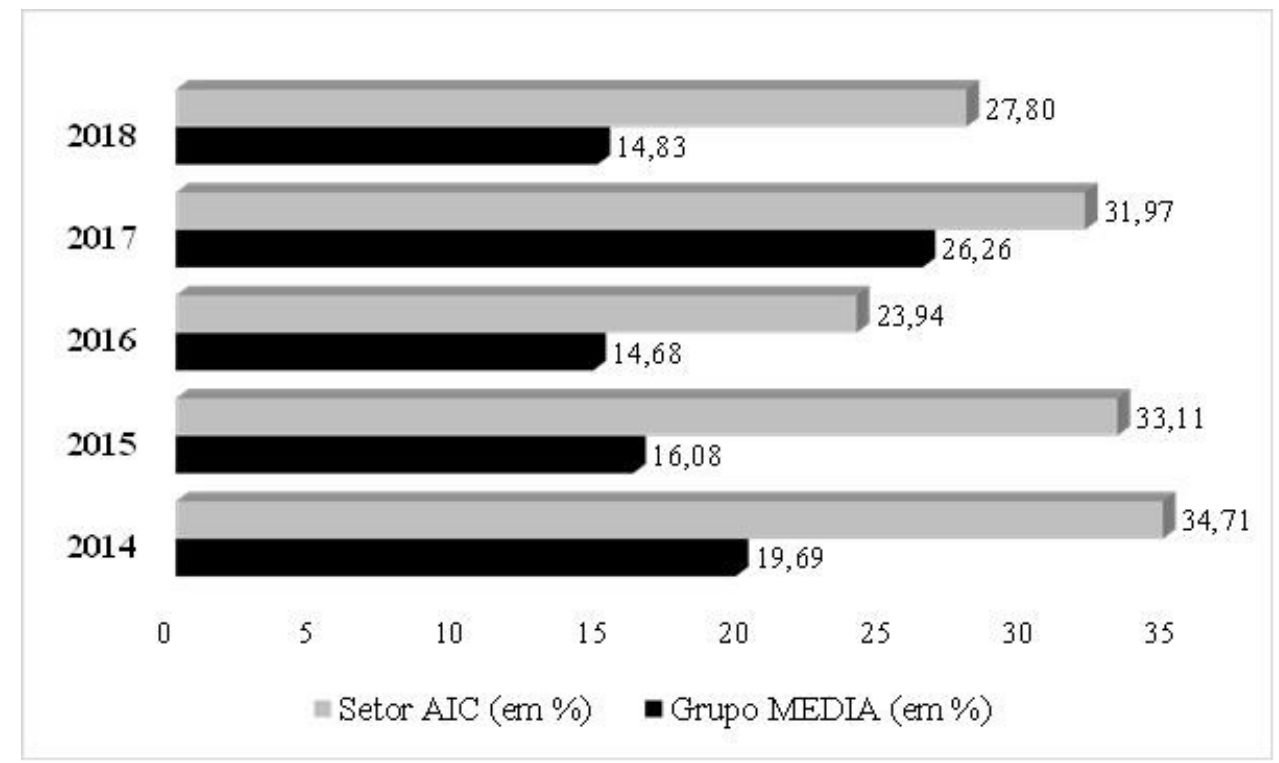

Figura 6. Evolução da AF no período 2014-2018

Fonte: Dados da pesquisa (2020).

Face aos resultados obtidos nos quatro indicadores analisados, verifica-se um cenário complexo face à realidade existente, no período em análise. Não sendo objetivo deste trabalho 
de investigação efetuar uma análise aprofundada da situação económico financeira do grupo, esta análise desenvolveu-se através de rácios e indicadores, que permitiram uma análise da evolução da atividade, em paralelo com a rendibilidade e $\mathrm{AF}$, procurando encontrar explicações para os valores encontrados.

De facto, no período 2014-2018, ao nível da solidez financeira, a empresa registou um significativo aumento dos gastos com indemnizações, aumento de investimentos, originando debilidades por via do elevado endividamento. Ao nível do desempenho económico, o grupo teve dificuldades em dinamizar o setor de vendas, devido à acentuada diminuição de vendas de publicações impressas, explicada pelo crescente desenvolvimento tecnológico, gerando uma consequente ineficácia de resultados que afetou a rendibilidade e, consequentemente, a sustentabilidade futura do grupo.

\subsection{Sistemas de Controlo de Gestão implementados entre 2014 e 2018}

\subsubsection{Controlo retrospetivo - Instrumentos de Pilotagem}

Durante o período em análise, os SCG utilizados pelo grupo MEDIA na fase de controlo retrospetivo, foram o processo orçamental e o BSC. No que respeita ao processo orçamental anual, este inicia-se entre meados de setembro e início de outubro, estando inteiramente dependente da estrutura do grupo.

$\mathrm{O}$ orçamento é elaborado considerando as diferentes empresas e os diferentes departamentos destas. Há, no entanto, atividades consideradas acessórias, que são transversais a todas as empresas e, como tal, apenas entram no orçamento da empresa-mãe. Exemplo destas atividades é o departamento jurídico, o departamento de recursos humanos, o departamento de serviços gerais, o departamento de qualidade, o departamento de PCG e o departamento financeiro.

As atividades consideradas operacionais, que resultam da atividade operacional normal destas empresas são orçamentadas atendendo às empresas a que respeitam. $\mathrm{O}$ orçamento destas atividades, apesar de refletir as diferentes empresas é elaborado pelo mesmo critério. É importante ressalvar que há departamentos que competem apenas a determinadas empresas, como, por exemplo, o departamento de marketing que apenas existe na empresamãe.

De seguida, a Figura 7, apresenta o mapa estratégico mais recente do grupo. 
Domingos, A. \& Mendonça, B.

As práticas de controlo de gestão e a performance financeira de um grupo português inserido no setor das atividades de informação e comunicação

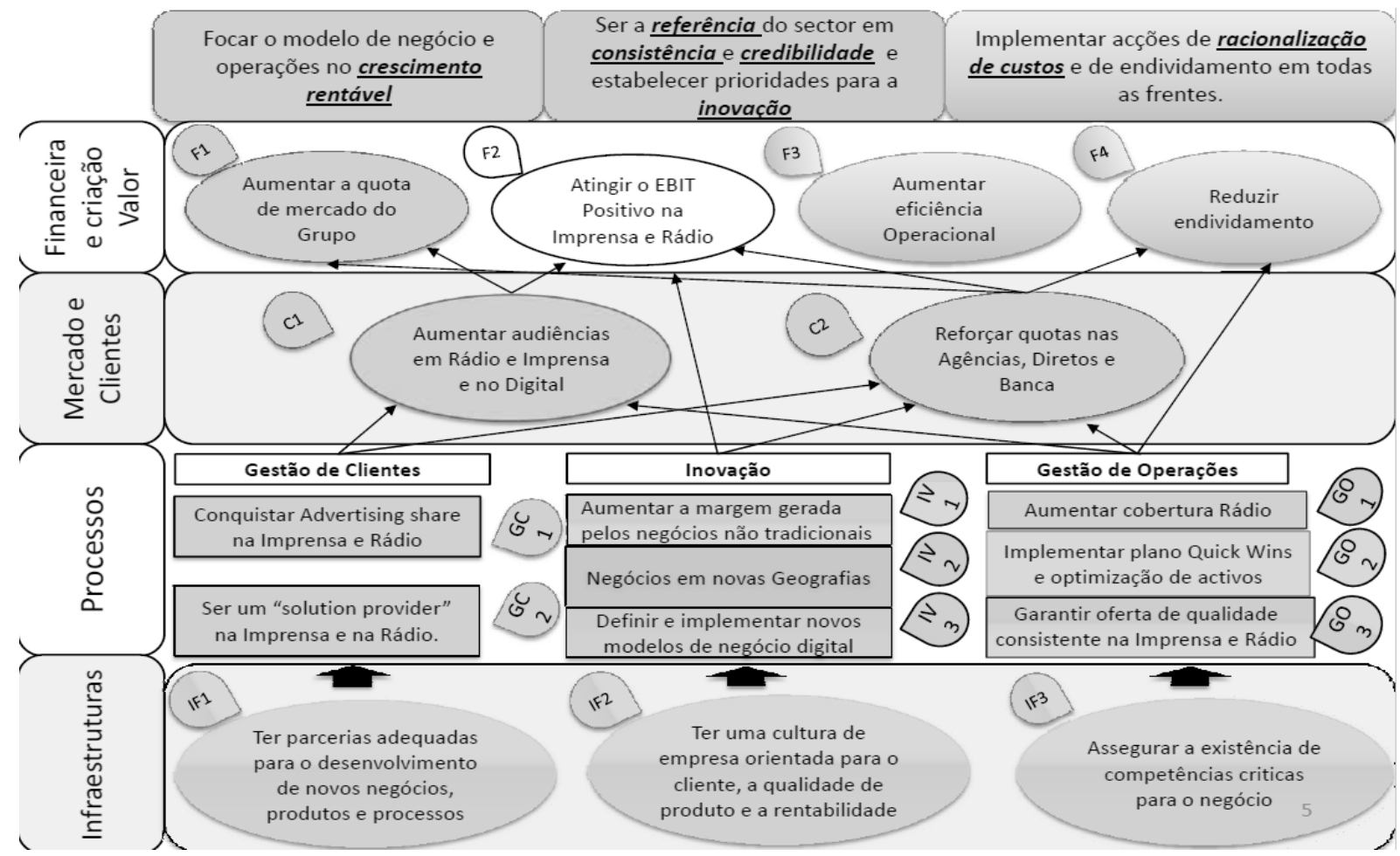

Figura 7. Mapa Estratégico do grupo Fonte: Documentos internos do grupo.

Da análise à Figura 7, salienta-se o facto de o grupo pretender atingir um EBIT positivo nas empresas detentoras dos jornais e na rádio, empresas com maior quota no grupo; pretender aumentar a eficiência operacional, uma vez que um dos grandes problemas do grupo tem sido a contratação e retenção de talentos criativos e produtivos, com formação para as redações editoriais.

Por sua vez, outros dos objetivos estratégicos é a redução do endividamento, tendo em conta que nos últimos anos o grupo tem vindo a enfrentar grandes dificuldades financeiras e o recurso a ajudas externas tem sido recorrente e crescente.

A Tabela 2 resume os tipos de atividades que são desenvolvidas no grupo MEDIA, os vários departamentos que existem, as fontes de informação que são utilizadas para a elaboração do orçamento, a quem pertence a responsabilidade pela sua elaboração e qual o departamento consultado para a sua elaboração. 
As práticas de controlo de gestão e a performance financeira de um grupo português inserido no setor das atividades de informação e comunicação

Tabela 2. Processo anual de orçamentação

\begin{tabular}{|c|c|c|c|c|}
\hline Atividades & Departamento & Fonte & Responsabilidade & Consulta \\
\hline \multirow{7}{*}{$\begin{array}{l}\text { Atividades } \\
\text { Acessórias }\end{array}$} & Jurídico & \multirow{6}{*}{$\begin{array}{c}\text { Histórico } \\
\text { retirado de Hyperion- } \\
\text { Oracle }\end{array}$} & \multirow{6}{*}{ PCG } & \multirow{6}{*}{$\begin{array}{l}\text { Diretores } \\
\text { (aprovações e } \\
\text { retificações) }\end{array}$} \\
\hline & $\begin{array}{l}\text { Recursos } \\
\text { Humanos }\end{array}$ & & & \\
\hline & Qualidade & & & \\
\hline & PCG & & & \\
\hline & Serviços Gerais & & & \\
\hline & Financeiro & & & \\
\hline & Informática & $\begin{array}{l}\text { Histórico retirado de } \\
\text { Hyperion-Oracle } \\
\text { Inputs de todos os } \\
\text { departamentos } \\
\text { /empresas do grupo }\end{array}$ & $\begin{array}{c}\text { Diretor do } \\
\text { departamento }\end{array}$ & $\begin{array}{l}\text { PCG (transposição da } \\
\text { informação para } \\
\text { moldes orçamentais) }\end{array}$ \\
\hline \multirow{5}{*}{$\begin{array}{c}\text { Atividades } \\
\text { Operacionais }\end{array}$} & Comercial & \multirow{2}{*}{$\begin{array}{l}\text { Histórico retirado de } \\
\text { Hyperion-Oracle }\end{array}$} & \multirow{2}{*}{$\begin{array}{c}\text { Diretor do } \\
\text { departamento }\end{array}$} & \multirow{2}{*}{$\begin{array}{l}\text { PCG (transposição da } \\
\text { informação para } \\
\text { moldes orçamentais) }\end{array}$} \\
\hline & Circulação & & & \\
\hline & Editorial & $\begin{array}{l}\text { Histórico retirado de } \\
\text { Hyperion-Oracle } \\
\text { Inputs de todos os } \\
\text { departamentos } \\
\text { editoriais }\end{array}$ & PCG & $\begin{array}{c}\text { Diretores de redações } \\
\text { (aprovação e } \\
\text { retificações) }\end{array}$ \\
\hline & Marketing & $\begin{array}{l}\text { Histórico retirado de } \\
\text { Hyperion-Oracle }\end{array}$ & $\begin{array}{c}\text { Diretor do } \\
\text { departamento }\end{array}$ & $\begin{array}{l}\text { PCG (transposição da } \\
\text { informação para } \\
\text { moldes orçamentais) }\end{array}$ \\
\hline & Comercial & $\begin{array}{l}\text { Histórico retirado de } \\
\text { Hyperion-Oracle } \\
\text { Inputs do } \\
\text { departamento } \\
\text { comercial }\end{array}$ & PCG & $\begin{array}{l}\text { Diretores de redações } \\
\text { (aprovação e } \\
\text { retificações) }\end{array}$ \\
\hline
\end{tabular}

Fonte: Elaboração Própria.

\subsubsection{Controlo prospetivo - Instrumentos de Orientação de Comportamento}

O ciclo da informação financeira, os seus utilizadores, as ferramentas que utilizam, as fases que a informação atravessa são importantes porque o acompanhamento dos resultados começa na fase em que são gerados.

A informação financeira do grupo MEDIA provém de inúmeras fontes internas e externas. As fontes externas, são os clientes e os fornecedores. As fontes internas do grupo são a Administração, os diversos departamentos financeiros das empresas do grupo, o departamento de recursos humanos, o departamento de informática, o departamento comercial, os serviços gerais de cada polo/edifício e as redações jornalísticas.

A Figura 8 apresenta, de forma sintética, o ciclo da informação financeira tanto a nível mensal como anual. 
As práticas de controlo de gestão e a performance financeira de um grupo português inserido no setor das atividades de informação e comunicação

\begin{tabular}{|c|c|c|}
\hline $\begin{array}{l}\text { Quem gera informação } \\
\text { financeira? }\end{array}$ & \multirow[b]{2}{*}{$\rightarrow$} & $\begin{array}{c}\text { Departamentos financeiros (empresas-filhas), Administração, } \\
\text { Departamento de Recursos Humanos, Departamento de } \\
\text { Informática, Departamento comercial, Redações, Serviços gerais, } \\
\text { clientes e fornecedores }\end{array}$ \\
\hline $\begin{array}{l}\text { Quem receciona a informação } \\
\text { financeira e a trabalha? }\end{array}$ & & $\begin{array}{l}\text { Departamento financeiro do grupo: área da Contabilidade, } \\
\text { Tesouraria, área de cobranças e faturação. }\end{array}$ \\
\hline $\begin{array}{l}\text { Como se receciona e trata a } \\
\quad \text { informação? } \\
\text { Que ferramentas são utilizadas? }\end{array}$ & $\rightarrow$ & $\begin{array}{c}\text { Correio eletrónico e postal; Easydocs, SAP, Plataforma de } \\
\text { colaborações, Ferramentas do Office }\end{array}$ \\
\hline $\begin{array}{l}\text { Quem receciona a informação } \\
\text { financeira depois de arquivada e } \\
\text { contabilizada? }\end{array}$ & $\rightarrow$ & Departamento do PCG e departamento fiscal \\
\hline Que ferramentas utilizam? & $\rightarrow$ & $\begin{array}{c}\text { Hyperion - Oracle e aplicações disponibilizadas pela Autoridade } \\
\text { Tributária }\end{array}$ \\
\hline $\begin{array}{l}\text { Quem receciona a informação } \\
\text { depois de agregada e analisada? }\end{array}$ & $\rightarrow$ & $\begin{array}{l}\text { Entidades Reguladoras Governamentais, Administração e } \\
\text { possíveis investidores/financiadores }\end{array}$ \\
\hline
\end{tabular}

Figura 8. Ciclo da informação financeira Fonte: Elaboração Própria.

A par do ciclo que a informação financeira percorre dentro da empresa, é importante referir, neste ponto, de que forma a informação é controlada e corrigida. Apesar de em todas as fases do percurso da informação financeira os intervenientes procurarem sempre a transferência da informação da forma mais autêntica e fiel, esta fase de controlo é da responsabilidade do departamento de PCG.

Este departamento controla, através de mapas e relatórios que elabora, se os dados reais estão a ir ao encontro do planeado. De seguida, é apresentado o processo que o departamento de PCG elabora - a nível mensal e, posteriormente, a nível anual. É importante ressalvar que a informação trabalhada pelo departamento de PCG é feita com base em informação contabilística, organizada por três dimensões, existindo uma listagem adaptada a cada uma das empresas do grupo. A análise é feita conforme funções (departamentos), produtos e na localização das atividades.

Processo Mensal - o processo está assente em quatro grandes atividades:

a) Dados Operacionais: consiste na preparação de ficheiros, com recurso à folha de cálculo Excel, que permitem analisar dados como o papel, matéria-prima essencial à impressão dos jornais, que são extraídos do SAP R/3, headcount de todas as empresas (dados enviados pelo departamento de Recursos Humanos), circulação e margens de dossiês de projetos, que são orçamentos de campanhas de marketing e de Projetos Especiais com Potencial Económico (PEPES);

b) Carregamentos: consiste na extração de informação contabilística do SAP R/3, na sua conversão e extração da informação do headcount em linguagem legível para que possa ser importada para o software Hyperion-Oracle. Para a conversão da informação em linguagem legível ao programa Hyperion-Oracle é utilizado um software desenvolvido internamente para o efeito.

c) Reporting: consiste na preparação de ficheiros que servirão de apoio à apresentação mensal e nos ficheiros posteriormente enviados às direções de cada departamento. Nesta fase, são preparados ficheiros de análise aos custos, rendimentos e quantidades 
do marketing (promocional, institucional, canais), às receitas das assinaturas digitais, aos PEPES, aos custos das redações editoriais, aos custos do departamento de informática, e aos custos dos novos negócios (área do grupo dedicada a plataformas digitais).

d) Apresentação: consiste na elaboração da apresentação dos resultados do grupo, diferenciados por empresas e produtos. A apresentação é apresentada à Administração pela diretora do departamento de PCG e devidamente discutidos os resultados.

Processo anual - a reavaliação orçamental, intitulada pelo grupo de forecasts deixou de ser efetuado a partir de 2016, de forma sistemática e organizada. Nos períodos de 2014 e 2015, o processo foi realizado de 6 em 6 meses, no qual era avaliado o panorama do país, dos diferentes departamentos e das perspetivas para o grupo até ao final do ano, a partir dessa data. Nas reavaliações de orçamento foram considerados acontecimentos como a perspetiva de entrada e saída de acionistas, bem como das suas entradas de capital, ou como o rebranding.

\subsubsection{Controlo integrado - Instrumentos de Diálogo}

Durante o período de 2014 a 2018, foram feitas apresentações, à Administração do grupo, tanto mensalmente como anualmente. Além dos membros da Administração e do PCG, representado pela sua diretora, estiveram presentes nestas reuniões tanto o diretor financeiro do grupo como os diretores de departamentos da empresa mãe e das restantes empresas.

Antes da realização da apresentação, é enviado pelo departamento de PCG às direções de departamentos/áreas, os relatórios descritivos de toda a informação que será abordada na reunião, em formato de TdB e com informação do conjunto de Key Performance Indicators (KPI) escolhidos pela direção do grupo. Estes relatórios têm o intuito de prestar informação atempada aos diretores para se prepararem para a reunião. Estas apresentações são elaboradas pelo departamento de PCG e, como apresentado na Tabela 3, abordam índices consolidados, valores por empresa/produto e ainda algumas informações adicionais.

Tabela 3. Apresentação mensal/anual

\begin{tabular}{|c|c|c|}
\hline 1. Consolidado & 2.Visão por Empresa e Meio & 3. Informação Adicional \\
\hline $\begin{array}{c}\text { EBITDA } \\
\text { Balanço } \\
\text { Resultado Líquido } \\
\text { Rendimentos operacionais } \\
\text { Circulação } \\
\text { Publicidade } \\
\text { Conferências e PEPEs } \\
\text { Gastos por natureza (variáveis e } \\
\text { fixos) } \\
\text { Gastos com pessoal } \\
\text { Capital Expenditure (CAPEX) } \\
\text { Cash Flow }\end{array}$ & $\begin{array}{c}\text { Apresentação dos mesmos } \\
\text { indicadores, } \\
\text { por empresa e produto }\end{array}$ & $\begin{array}{c}\text { Custos editoriais } \\
\text { Gastos com colaborações } \\
\text { Resultados do departamento de } \\
\text { marketing }\end{array}$ \\
\hline
\end{tabular}

Fonte: Documentos internos do grupo. 
Após serem apresentados os dados e indicadores financeiros, os diretores dos departamentos com maior peso nos resultados do grupo (circulação, marketing, comercial) fazem pequenos apontamentos acerca do que foi apresentado. Por fim, é aberto um espaço a questões e ao debate dos resultados.

\subsection{Análise crítica aos SCG implementados versus performance financeira}

Neste ponto, será efetuada uma análise crítica aos SCG existentes no grupo, tendo em conta as observações efetuadas pela autora, os documentos consultados e as informações recolhidas das reuniões realizadas.

Tendo como objetivo falar com alguém que tivesse um maior conhecimento sobre os SCG implementados pelo grupo ao longo do período em análise, a investigadora reuniu com o controller com mais anos de experiência profissional dentro do grupo. De acordo com as informações obtidas, existiram algumas tentativas de melhoramento do sistema de instrumentos de comportamento (fase de controlo prospetivo) e instrumentos de diálogo (fase de controlo integrado), uma vez que os mesmos têm vindo a tornar-se bastante obsoletos, pouco objetivos e com excessiva quantidade de informação.

Tem-se verificado que, por consequência destes dois instrumentos, os instrumentos de pilotagem (fase de controlo retrospetivo) tornaram-se inadequados à realidade do grupo. $\mathrm{O}$ controller considera que a performance financeira tem vindo a deteriorar-se ao longo do período em análise, em parte devido ao facto das tentativas de melhorias dos SCG não acompanharem as necessidades do grupo e pelo facto da visão de os utilizadores da informação gerada pelos SCG não estar a acompanhar a evolução que estes têm tido.

Por outro lado, de acordo com as informações extraídas da reunião com a contabilista certificada, verifica-se que esta tem uma perspetiva ligeiramente diferente, considerando que a performance financeira do grupo é resultado de falhas na implementação da fase de controlo integrado. Considera, também, que o grupo tem falhado na tomada de decisão (prova é a instabilidade do corpo acionista) perante a informação gerada pelos SCG e não na utilização dos mesmos. A contabilista certificada afirma que o grupo tem uma extensa gama de produtos a oferecer e que isso joga contra a sua performance, uma vez que se traduz numa extensa estrutura de gastos desnecessários, nomeadamente com pessoal.

Relativamente à análise crítica dos SCG implementados pelo grupo verificou-se, através das observações efetuadas, dos documentos analisados e das reuniões realizadas, que este é constituído por algumas empresas/marcas centenárias, tornando-se num grupo bastante familiar e com pouca abertura à mudança. Não obstante, salienta-se que, no período de 2014 a 2018, existiram numerosas tentativas de melhoria nos SCG.

Em 2014, o grupo sofreu uma restruturação, pelo que a sua estrutura de gastos diminuiu bastante resultante do despedimento coletivo existente nos departamentos com maior peso no grupo - editorial e comercial. Esta restruturação, que acabou por afetar a fase de controlo retrospetivo (orçamentos e forecasts), traduziu-se quantitativamente na melhoria dos indicadores de VN, EBITDA e RCP, nos períodos de 2014 e 2015.

Em 2015 e 2016, o grupo esforçou-se para melhorar, sobretudo na fase de controlo integrado. Aperfeiçoaram-se os moldes em que a informação financeira passou a ser reportada bem como começou a existir maior rede de discussão dessa mesma informação. Esta melhoria gerou, consequentemente, uma melhoria das fases de controlo retrospetivo e prospetivo dos períodos seguintes, traduzindo-se quantitativamente num aumento do $\mathrm{VN}$, da RCP e da $\mathrm{AF}$, comparativamente aos anos de 2016 e 2017. 
O período de 2018, foi um período atípico devido à grande restruturação ocorrida, originando uma evolução negativa nos indicadores financeiros face ao elevado esforço de tesouraria efetuado.

Face ao exposto, apresenta-se na Tabela 4, a relação entre os SCG implementados (adoção de novos instrumentos ou melhoria dos já existentes) e o comportamento da performance financeira do grupo, ao longo do período em análise.

Tabela 4. Relação entre os SCG implementados e a performance financeira (2014-2018)

\begin{tabular}{|r|r|r|r|r|r|r|}
\hline & $\mathbf{2 0 1 4}$ & $\mathbf{2 0 1 5}$ & $\mathbf{2 0 1 6}$ & $\mathbf{2 0 1 7}$ & $\mathbf{2 0 1 8}$ & $\mathbf{2 0 1 4 - 2 0 1 8}$ \\
\hline Número de SCG & 3 & 7 & 5 & 2 & \multicolumn{1}{c|}{5} & - \\
\hline Evolução do VN & - & $0,36 \%$ & $-3,72 \%$ & $-2,54 \%$ & $-6,51 \%$ & $-11,95 \%$ \\
\hline Evolução do EBITDA & - & $102,27 \%$ & $46,24 \%$ & $-374,26 \%$ & $-1050,40 \%$ & $-4,94 \%$ \\
\hline Evolução da RCP & - & $77,36 \%$ & $-11,93 \%$ & $26,77 \%$ & $-107,49 \%$ & $-15,29 \%$ \\
\hline Evolução da AF & - & $-3,61 \%$ & $-1,40 \%$ & $11,58 \%$ & $-11,43 \%$ & $-4,86 \%$ \\
\hline
\end{tabular}

Fonte: Dados da pesquisa (2020).

A Tabela 4 revela, que nos anos 2015 e 2016, anos em que houve um maior esforço em desenvolver os SCG existentes, foi quando se verificou um comportamento mais favorável em termos financeiros. Em 2017, não houve um investimento tão acentuado no desenvolvimento de SCG, tendo existido uma alteração do corpo acionista, justificando, desta forma, o aumento dos indicadores RCP e AF.

O ano de 2018, tendo sido um período de grande restruturação, acabou por afetar todas as fases de controlo e originado uma evolução negativa nos indicadores financeiros analisados, devido ao elevado esforço de tesouraria que o grupo efetuou. É relevante salientar que foi um período atípico, o que não reflete na totalidade o impacto da utilização positiva dos SCG e que comprova a teoria de que a performance financeira de uma organização está dependente de inúmeros fatores e não somente da existência de um SCG (Texeira, Antunes \& Quirós, 2015).

Deste modo, após a realização deste estudo, identificaram-se alguns aspetos do SCG que não foram adaptados ao longo do tempo à nova realidade do grupo. No ponto seguinte irão ser apresentadas algumas sugestões de melhoria do SCG, tendo por base, os instrumentos referidos e analisados anteriormente.

\subsection{Propostas de melhoria dos SCG atualmente existentes}

As propostas que se seguem, surgiram da experiência da autora e das informações recolhidas das reuniões realizadas. De um modo geral, verifica-se que os SCG existentes estão a ser bem utilizados, no entanto, alguns deles poderiam ser atualizados ou substituídos. Propõem-se, assim, as seguintes sugestões de melhoria:

\section{- Atualização da estrutura de centros de custos}

Atualmente, o grupo dispõe da mesma estrutura de organização de gastos e rendimentos de que dispunha há 10 anos. Esta estrutura de centros de custos é extensa, obsoleta e impeditiva, por vezes, de uma boa interpretação e análise da informação que é agregada com base nesta estrutura. 
$\mathrm{Na}$ fase de controlo retrospetivo, a proposta baseia-se na simplificação da estrutura de centros de custos, o que por sua vez simplificaria a elaboração e a apresentação da estrutura de gastos e rendimentos orçamentados.

O grupo dispõe de um leque de mais de 6000 centros de custos, verificando-se que, numa base mensal apenas são utilizados cerca de 100. A estrutura está dividida por grupos em 24 áreas operacionais e 6 grupos de centros de custos relativos a fusões, centros de custos agregadores, entre outros.

Os centros de custos decompõem-se em 9 dígitos, sendo a sua composição referente: ao tipo de gasto/rendimento a que se refere ( 3 dígitos), ao produto/publicação ( 2 dígitos), ao tipo de meio de venda, se digital se físico (2 dígitos); e, por fim, à localização geográfica da empresa em Portugal Continental (2 dígitos).

A Figura 9 ilustra a estrutura de um centro de custos existente no grupo. Assim, o centro 100010101 refere-se ao tipo de gasto, que no caso é um gasto relativo a publicidade (100), à publicação x (01), distribuída na forma física (01) e relativo à redação que está localizada em Lisboa (01).

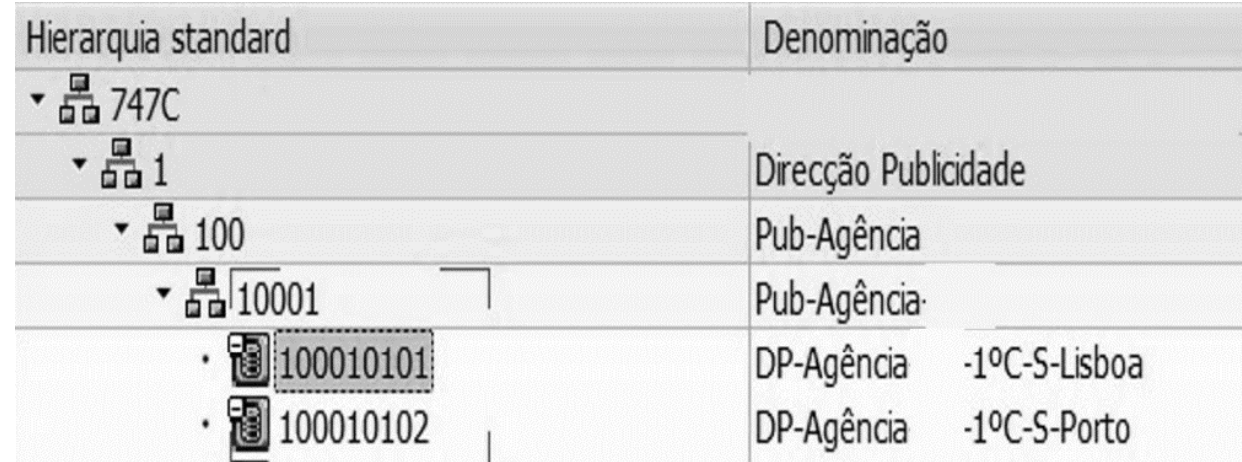

Figura 9. Estrutura do centro de custos da Direção de Publicidade

Fonte: Dados internos do grupo.

Para além desta estrutura estar a ser manuseada por muitas pessoas, o grupo não segue à risca as regras que determinou inicialmente para a criação dos centros de custo. Talvez devido a alguma ausência de informação na forma de organização e de manuseamento, a composição dos centros de custo tem vido a tornar-se obsoleta. Identificaram-se alguns dos motivos:

- a incoerência na criação dos centros de custos. Como ilustrado na Figura 10, o grupo utiliza o centro de custos 910012402, que se refere a custos de publicidade de uma publicação, associada ao departamento de Negócio Eletrónico da redação localizada no Porto. Além da estrutura deste centro de custos não obedecer às regras definidas inicialmente, os custos imputados a este centro são, unicamente, custos de publicidade associados a esta publicação, os quais poderiam ser associados a um centro de custos 100 . 


\begin{tabular}{|c|c|}
\hline Hierarquia standard & Denominação \\
\hline \multicolumn{2}{|l|}{ 量 $747 C$} \\
\hline , 㫛 1 & Direcção Publicidade \\
\hline - 是 2 & Direcção Distribuição \\
\hline - 莡 3 & Direcção Marketing \\
\hline , 蓸 4 & Direcção Qualidade \\
\hline '最 5 & Direcção Assinaturas \\
\hline , 最 6 & Direcção Produção \\
\hline , 昂 7 & Direcção Editorial \\
\hline , 㫛 8 & Direç̧ão Estudos e Projectos \\
\hline 㫛 9 & Direcção Negocio Electronico-Multimedia \\
\hline 莡 900 & Dir. Negocio eletronico e multimedia \\
\hline 㫛 910 & DNEM Publicidade Agencias \\
\hline 㫛 91001 & DNEM Publicidade Agencias \\
\hline ·闻 910012401 & DNEM Publicidade Agencias \\
\hline ·睷 910012402 & DNEM-Publicidade Site $\quad$-Porto \\
\hline
\end{tabular}

Figura 10. Estrutura dos centros de custo Direção de Negócio Eletrónico - Multimédia Fonte: Dados internos do grupo.

A ideia era que existisse uma equipa que escrevesse para determinado jornal em Lisboa e outra equipa localizada no Porto, isto é, que escrevessem para o mesmo jornal, mas tendo por base localizações diferentes, logo a informação obtida seria diferente e mais próxima à zona. Desta forma, os custos seriam separados por quem os gerasse. No entanto, não existe uma equipa localizada no Porto, somente em Lisboa, a qual sempre que necessário se desloca ao Porto, logo o centro de custos indicativo da localização do Porto nunca é utilizado, não fazendo sentido existir. Não obstante, atualmente, aparece sempre nos relatórios, com valor zero.

- O leque de produtos/publicações já foi drasticamente renovado ao longo das duas últimas décadas, bem como ocorreu a aquisição e alienação de empresas, não tendo a estrutura de gastos sido atualizada.

- Existe uma extensa lista de centros de custos para o mesmo tipo de gastos, sem justificação plausível.

- A estrutura está dividida por diferentes localizações (Lisboa, Porto, Minho, Norte e Sul), quando na prática todas as sedes/redações estão centralizadas em Lisboa e apenas duas em São Miguel, nos Açores.

Os relatórios financeiros são, até aos dias de hoje, elaborados tendo por base a totalidade dos centros de custos e não apenas aqueles que são geradores de informação útil, produzindo, assim, excesso de informação desnecessária.

Desta forma, sugere-se que relativamente à divisão da estrutura por grupos de centros de custos, que sejam avaliadas as áreas que fazem sentido na atividade prática do grupo, como por exemplo eliminar o grupo de Direção Negócio Eletrónico, uma vez que já existe a decomposição de todos os custos associados a esta área nos outros grupos (custos de publicidade, custos de marketing) e já existe a indicação da associação a uma publicação digital.

Relativamente à decomposição dos centros de custos, a sugestão é de que seja feita em 7 dígitos, nomeadamente: 
- tipo de gasto/rendimento a que se refere (3 dígitos);

- produto/publicação (2 dígitos);

- tipo de meio de venda, se digital se físico (2 dígitos).

O resultado que se pretende com a aplicação desta nova estrutura é um menor dispêndio de tempo na interpretação e análise da informação, face ao que acontece atualmente. $\mathrm{Na}$ fase de controlo prospetivo, a simplificação da estrutura de centros de custos simplificaria, de forma operacional, o registo da informação financeira.

- Substituição do software de agregação da informação analítica e do software de planeamento, orçamentação e forecasting

Uma vez que o setor das tecnologias de informação está em permanente mudança, a atualização do software deve ser uma preocupação para que as empresas possam encontrar novos programas que possam atender melhor às suas necessidades.

Assim, a segunda proposta de melhoria passa pela atualização tanto do software desenvolvido internamente em 2001 e sem nunca ter sofrido nenhuma atualização desde então - utilizado para a conversão da informação financeira exportada de SAP R/3, como do software de planeamento, orçamentação e forecasting - Hyperion-Oracle - o qual se tem mostrado uma ferramenta de difícil manuseamento, pouco intuitiva e por vezes limitativa e lenta.

Esta sugestão deve-se ao facto deste software mais antigo não apresentar as soluções necessárias para os problemas atuais do grupo, uma vez que, quando foi adquirido, as exigências do mercado e das empresas do grupo eram outras. Para além disso, existe a questão da segurança. Um programa que não possui atualizações recentes acaba por estar mais exposto ao risco de ataques de hackers ou à perda de dados importantes para a empresa. Pretende-se, assim, que esta necessidade não seja encarada como apenas "mais um gasto desnecessário", mas sim como um investimento no software que mais se adequa à realidade atual do grupo e ao auxílio na prestação da informação necessária à tomada de decisão.

Sendo que, hoje, as empresas necessitam de um SCG adequado à sua realidade, que lhes permita conceber planos de ação e relatórios de acompanhamento e acompanhar a evolução da sua performance, uma sugestão de software a adquirir seria o Power BI. Este software tem-se evidenciado no contexto empresarial, sendo considerado uma ajuda importante, pois permite sintetizar a informação definida como relevante, através de múltiplas recolhas e análises, elaboração de relatórios e apresentações visuais e interativas. Uma vez que a informação deixa de ser plana e passa a ser circular e relacional, todos os intervenientes passariam a ter acesso à informação adequada e em tempo útil, possibilitando a leitura em tempo real, compreendendo o nível de desempenho de cada departamento, equipa ou colaborador, com segurança e níveis de acesso diferenciados.

- Apresentação dos orçamentos e posteriores resultados aos colaboradores.

$\mathrm{Na}$ fase de controlo integrado, a proposta é de que os resultados e os orçamentos fossem apresentados aos colaboradores (consoante os seus departamentos/empresas), de modo a garantir que todos estão a trabalhar para os mesmos objetivos que o grupo, criando, talvez, um espaço de diálogo para entender as suas necessidades e objetivos pessoais.

Devido ao processo de reestruturação verificado no grupo, com forte redução de pessoal, considera-se fundamental fomentar uma cultura de comunicação e colaboração. Neste sentido, seria importante a comunicação aos colaboradores do mapa estratégico, de 
forma que se tornasse evidente para todos na organização a ligação entre os diferentes fatores que condicionam a implementação da estratégia. Assim, assegurava-se que os comportamentos e decisões dos colaboradores são consistentes com os objetivos e estratégias do grupo. Talvez, desta forma, fosse possível agir em tempo útil sobre acontecimentos que embora não estejam a ter impacto direto no curto prazo sobre os resultados da empresa, podem vir a condicionar a sua sustentabilidade num futuro próximo. Para além disso, num grupo que atua num setor de atividade composto por divulgação de informação, onde as inovações ocorrem permanentemente, a partilha de informação é fundamental.

Se cada responsável souber o que é esperado de si, mais facilmente trabalha para atingir os seus objetivos e, consequentemente, para os objetivos do grupo. Se existirem, por exemplo, planos operacionais, direcionados a cada departamento, que se responsabilizam pelo cumprimento dos objetivos a que eles próprios se propõem, consegue-se implementar a delegação de responsabilidades. Isto é, o colaborador irá focar-se nas suas atividades e traduzirá uma maior motivação na execução das suas funções. Desta forma, o orçamento deixa de ser um instrumento de informação, e passa a ser um instrumento que guia toda a organização para a realização dos objetivos.

Seguem-se algumas sugestões para alcançar esta relação de comunicação e colaboração dentro do grupo:

- Reuniões anuais, por departamento ou por áreas associadas, dirigidas em conjunto pelo órgão de gestão e pelos diretores intermédios, a fim de apresentar os resultados do período anterior, bem como apresentar os objetivos que o grupo se compromete a alcançar em específico nesta área identificando, de forma prática, como os pretende alcançar.

Seria relevante que, nestas reuniões, os colaboradores tivessem um espaço de partilha de informação de modo que se possam entender as dificuldades e frustrações que cada departamento tem vindo a sentir. Seria, também, útil saber que ferramentas os colaboradores consideram essenciais para que, operacionalmente, consigam alcançar os objetivos que o órgão de gestão definiu;

- Reuniões individuais, numa base anual, dirigida pelos responsáveis de cada área, a fim de entender os objetivos pessoais dos colaboradores;

- Convívios entre departamentos/áreas de modo a fomentar o espírito de entreajuda e aumentar a comunicação;

- Comunicações internas acerca da estrutura do grupo, que até então são bastante reduzidas, como é o caso da alteração do corpo acionista, da criação de novos produtos e da criação de novos departamentos.

Com uma estrutura bem delineada e com uma equipa de trabalho multidisciplinar (não só o controller) espera-se que, com a implementação das medidas propostas, passe a existir uma melhoria substancial na qualidade da informação para a gestão e, consequentemente, na competitividade do grupo.

\section{CONSIDERAÇÕES FINAIS}

Ao longo dos anos, os SCG têm evoluído de forma a adaptarem-se às necessidades da informação para a gestão, fruto das transformações ocorridas no ambiente interno e externo das organizações. Da revisão da literatura efetuada conclui-se que, a utilização de qualquer SCG contenha ele unicamente indicadores financeiros ou indicadores financeiros e não financeiros, trará diversos benefícios a qualquer empresa. Contudo, quanto mais completo e 
minucioso for, mais proveitoso será para a empresa e para os seus gestores, logo garantirá maior qualidade na tomada de decisão.

Alguns autores, como Silva (2018), Duréndez et al. (2006), Morais (2016), Texeira, Antunes e Quirós (2015), Muanha (2014) e Rendas (2013), desenvolveram estudos sobre as relações existentes entre os SCG implementados, as estratégias seguidas e a performance das empresas. Seguindo a linha de investigação destes autores, $o$ presente trabalho de investigação teve como objetivo analisar a influência da utilização de SCG, implementados por um grupo português de empresas inserido no setor das AIC, segmento de atividade dos media, na sua performance financeira, durante o período de 2014 a 2018.

Verificou-se que o grupo dispõe de um leque de instrumentos, sendo estes apresentados consoante a fase de controlo a que pertencem: fase de controlo retrospetivo, prospetivo e integrado.

No período de 2014, ano em que o grupo sofreu uma restruturação (ou seja, ano em que houve alterações nos SCG na fase de controlo retrospetivo), observou-se uma melhoria dos indicadores de VN, EBITDA e RCP. Este padrão de melhoria nestes indicadores manteve-se no período de 2015.

Nos períodos de 2015 e 2016, anos em que houve um maior esforço em desenvolver os SCG existentes, sobretudo a fase de controlo integrado, foi quando se verificou um comportamento mais favorável em termos financeiros. Nesta fase, melhoraram-se os moldes em que a informação financeira passou a ser reportada, bem como começou a existir maior rede de discussão dessa mesma informação. Este progresso gerou, consequentemente, uma melhoria das fases de controlo retrospetivo e prospetivo dos períodos seguintes, traduzindo-se quantitativamente num aumento do VN, da RCP e da AF.

Em 2017, não houve um investimento tão acentuado no desenvolvimento de SCG, tendo existido uma alteração do corpo acionista, justificando, desta forma, o aumento dos indicadores RCP e AF.

Por fim, o ano de 2018, tendo sido um período de grande restruturação, acabou por afetar todas as fases de controlo e originado uma evolução negativa nos indicadores financeiros analisados, devido ao elevado esforço de tesouraria que o grupo efetuou.

Face ao exposto na literatura, e de acordo com a documentação consultada, observações efetuadas e as reuniões efetuadas, foram propostas algumas sugestões de melhoria que poderão contribuir positivamente para os SCG do grupo: (i) atualização da estrutura de centros de custos; (ii) substituição do software de agregação da informação analítica e do software de planeamento, orçamentação e forecasting; e (iii) apresentação dos orçamentos e posteriores resultados aos colaboradores.

Em resposta à questão de investigação, com base na revisão de literatura efetuada e com base nos dados recolhidos na presente investigação, ao longo do período 2014-2018, não é possível afirmar que a intensidade da utilização mais elevada de SCG conduziu a melhores resultados financeiros. Tal como Texeira, Antunes e Quirós (2015) e Morais (2016) referiram, a implementação de SCG por si só não melhora a rendibilidade. Conclui-se, assim, que uma maior utilização de SCG está associada à obtenção de melhores resultados, mas não se pode afirmar que a sua existência, em detrimento de outras variáveis, conduz a uma performance financeira superior, tal como concluiu Rendas (2013).

Neste trabalho procurou-se acrescentar evidência científica que contribuirá para ajudar as empresas deste setor a deterem informação contabilística que responda oportunamente às necessidades da gestão, analisando a relação entre a adoção de práticas de CG e a sua influência na performance financeira. Não obstante, existem limitações que lhe estão 
associadas. A primeira tem a ver com o facto de se tratar de um estudo de caso, condicionando a generalização das conclusões do estudo. A outra limitação tem a ver com o facto de, apesar de muitas empresas implementarem vários tipos de SCG com o intento destes melhorarem o seu desempenho existe, ainda, pouca evidência empírica sobre a eficácia destas ferramentas nos resultados obtidos pelas organizações. Esta lacuna, conjugada com as conclusões apresentadas, permitem identificar sugestões para investigações futuras que potenciem um melhor entendimento desta realidade.

Desta forma, apesar de existirem alguns estudos que apontam para uma relação positiva entre a implementação de SCG nas empresas e a sua rendibilidade, não é claro quais os fatores determinantes para a melhoria dessa rendibilidade e quais as técnicas de $\mathrm{CG}$ associadas. Assim, seria importante compreender quais as ferramentas de CG que mais impacto têm na rendibilidade das empresas.

\section{REFERÊNCIAS}

Anthony, R. \& Govindarajan, V. (2007). Management Control Systems. (12. ${ }^{a}$ ed.). Nova York: Irwin McGraw-Hill.

Banco de Portugal (2014). Análise do setor das atividades de informação e comunicação.

Estudos da Central de Balanços. Consultado em 2 de dezembro de 2020. Disponível em: https://www.bportugal.pt/sites/default/files/anexos/pdf-

boletim/estudos $\% 20 \mathrm{da} \% 20 \mathrm{cb} \% 2016$ 2014.pdf

Banco de Portugal (2014). Estudo da Central de Balanços | 16 - Análise do setor das Atividades de Informação e Comunicação. Consultado em 2 de dezembro de 2020. Disponível em: https:/www.bportugal.pt/sites/default/files/anexos/documentosrelacionados/nie estudo\%20 $\%$ b $\% 2016$ 2014.pdf

Banco de Portugal (2016). Análise do setor das atividades de informação e comunicação 2011-2016. Consultado em 2 de dezembro de 2020. Disponível em: https://www.bportugal.pt/sites/default/files/anexos/documentosrelacionados/nie estudo 16 2014.pdf

Barros, R. \& Ferreira, A. (2019). Bridging management control systems and innovation: the evolution of the research and possible research directions. Qualitative Research in Accounting and Management. 16(3), 342-372. Disponível em: http://hdl.handle.net/10071/19987.

Duréndez, A., Palomo, D., Pérez-de-Lema, D. \& Soto, J. (2016). Management Control Systems and Performance in Small and Medium Family Firms. European Journal of Family Business 6 (1), 10-20.

Jordan, H., Neves, J. \& Rodrigues, J. (2015). O Controlo de Gestão ao Serviço da Estratégia e dos Gestores (10. ${ }^{a}$ ed.). Lisboa: Áreas Editora.

Kaplan, R. \& Norton, D. (1992). The Balanced Scorecard: Measures that Drive Performance. Harvard Business Review, 70(1), 71-79.

Malmi, T. \& Brown, D. (2008). Management control systems as a package-Opportunities, challenges and research directions. Management Accounting Research, 19(4), 287- 287300. doi:10.1016/j.mar.2008.09.003 
Merchant, K. \& Van der Stede, W. (2012). Management control systems: performance measurement, evaluation and incentives ( $\left.3 .^{\mathrm{a}} \mathrm{ed}\right)$. Harlow: Pearson Education.

Morais, A. (2016). A relação entre os sistemas de controlo de gestão e a performance financeira das farmácias comunitárias portuguesas (Dissertação de mestrado, Lisbon School of Economics \& Management, Lisboa, Portugal). Disponível em https://www.repository.utl.pt/handle/10400.5/13145

Muanha, S. (2014). Condicionantes do Controlo de Gestão nas Organizações: uma análise da Performance das Organizações Financeiras (Dissertação de mestrado, Instituto Superior de Gestão, Lisboa, Portugal). Disponível em: https://comum.rcaap.pt/handle/10400.26/9436

Rendas, S. (2013). Sistemas de Controlo de Gestão, Estratégia e desempenho financeiro de empresas de hotelaria. (Dissertação de mestrado, Instituto Superior de Economia e Gestão, Lisboa, Portugal). Disponível em: https://www.repository.utl.pt/handle/10400.5/8545

Silva, S. (2018). O Controlo de Gestão e o desempenho organizacional - estudo de caso: a relação da sua dependência no setor empresarial. (Dissertação de mestrado, Instituto Superior de Contabilidade e Administração do Porto, Porto, Portugal). Disponível em: https://recipp.ipp.pt/bitstream/10400.22/13003/1/sara_silva_MA_2018.pdf.pdf

Texeira, M., Antunes, M. \& Quirós, J. (2015) Os Sistemas de Controlo de Gestão, A Gestão Da Qualidade Total e a Inovação - Efeitos no Desempenho Organizacional. Atas do XV Congresso Internacional de Contabilidade e Auditoria - A Contabilidade e o interesse público. Disponível em: http://hdl.handle.net/10400.21/8168

Ussahawanitchakit, P. (2017). Management control systems and firm sustainability: evidence from textile and apparel businesses in Thailand. Asian Academy of Management Journal, 185-208.

Vieira, R., Major, M. \& Robalo, R. (2009). Investigação Qualitativa em Contabilidade, in Major, M.; Vieira, R. (Eds.), Contabilidade e Controlo de Gestão: Teoria, Metodologia e Prática. Escolar Editora, Lisboa, (pp. 131-163). Lisboa: Escolar Editora.

Yin, R. (2018): Estudo de Caso: planejamento e métodos (5. a ed.). Porto Alegre: Bookman. 